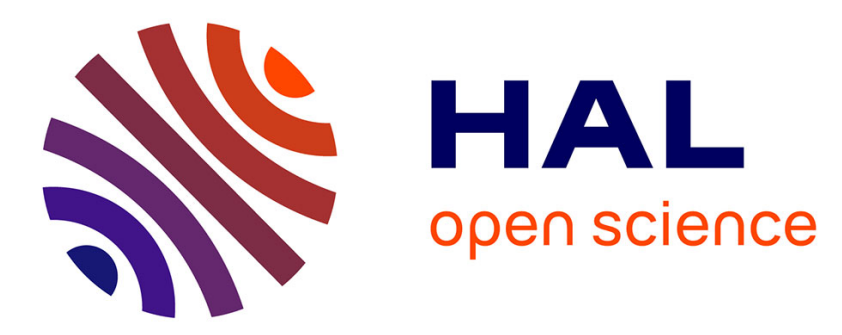

\title{
Effect of pedalling rates on physiological response during endurance cycling
}

\author{
R. Lepers, G. Y. Millet, N.A. Maffiuletti, Christophe Hausswirth, Jeanick \\ Brisswalter
}

\section{- To cite this version:}

R. Lepers, G. Y. Millet, N.A. Maffiuletti, Christophe Hausswirth, Jeanick Brisswalter. Effect of pedalling rates on physiological response during endurance cycling. European Journal of Applied Physiology, 2001, 85 (3-4), pp.392-395. 10.1007/s004210100465 . hal-01760198

\section{HAL Id: hal-01760198 https: / hal-insep.archives-ouvertes.fr/hal-01760198}

Submitted on 6 Apr 2018

HAL is a multi-disciplinary open access archive for the deposit and dissemination of scientific research documents, whether they are published or not. The documents may come from teaching and research institutions in France or abroad, or from public or private research centers.
L'archive ouverte pluridisciplinaire HAL, est destinée au dépôt et à la diffusion de documents scientifiques de niveau recherche, publiés ou non, émanant des établissements d'enseignement et de recherche français ou étrangers, des laboratoires publics ou privés. 


\title{
Effect of pedalling rates on physiological response during endurance cycling
}

\author{
R. Lepers ; G.Y. Millet ; N.A. Maffiuletti ; C. Hausswirth ; J. Brisswalter
}

\begin{abstract}
R. Lepers ; G.Y. Millet; N.A. Maffiuletti: Groupe Analyse du Mouvement, Unité de Formation et de Recherche en Science et Techniques des Activités Physiques et Sportives, Université de Bourgogne, BP 27877,21078Dijon, France-E-mail: romuald.lepers@u-bourgogne.fr Tel.: + 33-3-80396760 ; Fax: + 33-3-80396702

C. Hausswirth: Laboratoire de Biomécanique et de Physiologie, Institut National du Sport et de l'Education Physique, 75012 Paris, France
\end{abstract}

J. Brisswalter : Université de Toulon-Var, Unité Ergonomie Sportive et Performance, BP 132, 83957 La
Garde, France

Article publié dans : European journal of applied physiology, 2001, vol. 85, n³-4, pp. 392-395

\begin{abstract}
This study was undertaken to examine the effect of different pedalling cadences upon various physiological responses during endurance cycling exercise. Eight well-trained triathletes cycled three times for $30 \mathrm{~min}$ each at an intensity corresponding to $80 \%$ of their maximal aerobic power output. The first test was performed at a freely chosen cadence (FCC); two others at FCC- $20 \%$ and FCC $+20 \%$, which corresponded approximately to the range of cadences habitually used by road racing cyclists. The mean (SD) FCC, FCC-20\% and FCC + 20\% were equal to 86 (4), 69 (3) and 103 (5) rpm respectively. Heart rate (HR), oxygen uptake (VO2), minute ventilation (VE) and respiratory exchange ratio $(R)$ were analysed during three periods: between the 4th and 5th, 14th and 15th, and 29th and 30th min. A significant effect of time $(P<0.01)$ was found at the three cadences for $\mathrm{HR}, \mathrm{VO}_{2}$. The $\mathrm{V}_{\mathrm{E}}$ and $R$ were significantly $(P<0.05)$ greater at FCC $+20 \%$ compared to FCC-20\% at the 5 th and 15 th min but not at the 30th min. Nevertheless, no significant effect of cadence was observed in HR and $\mathrm{VO}_{2}$. These results suggest that, during high intensity exercise such as that encountered during a time-trial race, well-trained triathletes can easily adapt to the changes in cadence allowed by the classical gear ratios used in practice.
\end{abstract}

Keywords Cadence / Oxygen uptake / Triathletes / Fatigue

\section{Introduction}

During training or racing, experienced cyclists or triathletes usually select a relative high pedalling cadence, close to $80-90 \mathrm{rpm}$. The reasons behind the choice of such a cadence are still controversial and are certainly multi-factorial. Several assumptions relating to neuromuscular, biomechanical or physiological parameters have previously been proposed.

The concept of a most economical cadence is generally supported by experiments where cadences have been varied from the lowest to the highest rates and a parabolic oxygen uptake $\left(\mathrm{VO}_{2}\right)$-cadence relationship has been obtained. Nevertheless in reality, extreme cadences such as 50 or $110 \mathrm{rpm}$ are very rarely used by road cyclists or triathletes. Simple observations have shown for example that on a flat road at $40 \mathrm{~km} \cdot \mathrm{h}^{-1}$ cadences ranged from $67 \mathrm{rpm}$ with a 53:11 gear ratio (GR) to $103 \mathrm{rpm}$ with a 53:17 GR. During an up-hill climb at $20 \mathrm{~km} \bullet \mathrm{h}^{-}{ }^{1}$, cadences ranged from $70 \mathrm{rpm}$ with a 39:17 GR to 103 rpm with a 39:25 GR. Thus, the range of cadences adopted by cyclists using these common GR may vary from 70 to $100 \mathrm{rpm}$, which corresponds to approximately $85 \mathrm{rpm} \pm 20 \%$.

The effect of exercise duration upon cycling cadence has not been well studied. The freely chosen cadence (FCC) has seemed to be relatively stable during high intensity cycling exercise of $30 \mathrm{~min}$ duration (Brisswalter et al. 2000) but the FCC was found to decrease during $2 \mathrm{~h}$ of cycling at submaximal intensity (Lepers et al. 2000). In a non fatiguing situation, the FCC is known to be higher than the most economical cadence. However, a shift in the energetically optimal rate during exercise 
towards the FCC has recently been reported by Brisswalter et al. (2000). These observations raise a question concerning the choice of any particular GR by road racing cyclists and thus of a pedalling rate and the physiological consequences of this choice for exercise duration .

Therefore, the purpose of this study was to investigate whether the use of cadences $20 \%$ lower or higher than the freely chosen one during high intensity endurance exercise induced different changes in metabolic parameters as fatigue occurred.

\section{Methods}

\section{Subjects}

Eight well-trained male triathletes volunteered to participate in this study. The physical characteristics of the subjects are given in Table 1. They were informed in detail of the experiment and gave written consent prior to all tests.

\section{Experiment procedures}

Each subject completed four tests during a 3 week period. Each session was separated by at least $72 \mathrm{~h}$. AH experiments were conducted using an electromagnetically braked cycle ergometer (Type Excalibur, Lode, Groningen, The Netherlands) of which the seat and handlebars are fully adjustable to the subject's dimensions. The ergometer was also equipped with racing pedals, and toe clips allowing the subjects to wear cycling shoes. The first session was used to determine the maximal oxygen uptake (VO2max) of the subjects. The $\mathrm{V}_{2 \max }$ test began with a warm-up at $100 \mathrm{~W}$ lasting 6 min, after which the power output was increased by $25 \mathrm{~W}$ every $2 \mathrm{~min}$ until the subjects were exhausted. The three other sessions were composed of a 10 min warm-up ride followed by a 30 min submaximal test at $80 \%$ of the highest power sustained for $2 \min \left(\mathrm{P}_{\max }\right)$. The first of these three sessions was performed at the FCC which corresponded to the cadence that the subjects spontaneously adopted within the first 5 min. During the last $25 \mathrm{~min}$ of this test, subjects were asked to maintain a similar cadence. For the two other tests, subjects rode in a random order at FCC- $20 \%$ or FCC $+20 \%$. The heart rate (HR) was monitored continuously, and gas exchanges were collected at three periods: between the 4th-5th (period 1), the 14th-15th (period 2), and 29th-30th (period 3) min. The $\mathrm{HR}, \mathrm{VO}_{2}$, minute ventilation $\left(\mathrm{V}_{\mathrm{E}}\right)$ and respiratory exchange ratio $(R)$ for these three periods were analysed.

Statistical analysis

A two-way ANOVA (time $\mathrm{x}$ cadence) was performed using HR, VO2, VE and $R$ as dependent variables. When a significance of $P<00.05$ was obtained using the ANOVA, Tukey post-hoc multiple comparisons were made to determine differences either among pedal rates or among periods.

\section{Results}

Mean (SD) FCC were 86 (4) rpm, therefore FCC-20\% and FCC + 20\% corresponded to 69 (3) and 103 (5) rpm, respectively (Table 1).

A significant time effect $(P<0.01)$ was found at the three cadences in HR, VE (Table 2). The rise in $\mathrm{VO}_{2}$ between the 5th and the 30th min corresponded to $11.0(7.4) \%, 10.3(6.9) \%$ and $9.9(3.7) \%$ at FCC- $20 \%$, FCC and FCC $+20 \%$, respectively. Between the 5th and the 30th min VE increased by 35.4 $(17.4) \%, 28.7(10.9) \%$ and $21.2(5.2) \%$ at FCC-20\%, FCC and FCC $+20 \%$, respectively. No significant differences appeared among the three cadences.

A significant effect of cadence was found in $\mathrm{V}_{\mathrm{E}}$ and $R$ in the first part of the exercise (Table 2). Posthoc tests showed that $\mathrm{V}_{\mathrm{E}}$ was significantly greater at FCC $+20 \%$ compared to FCC-20\% at the 5th and 15 th min but not at the 30th min. Similarly, $R$ was significantly greater at FCC $+20 \%$ in comparison to FCC-20\% and FCC at the 5th and 15th min but not at the 30th min. In $\mathrm{VO}_{2}$ and $\mathrm{HR}$, no significant effect of cadence was observed. 


\section{Discussion}

The main finding of this study was the absence of significant differences in physiological parameters among the three different pedalling rates (FCC, FCC-20\% and FCC $+20 \%$ ) despite a significant effect of exercise duration.

Increases in $\mathrm{HR}, \mathrm{VO}_{2}$ and $\mathrm{V}_{\mathrm{E}}$ at the end of 30 min of cycling at $80 \%$ of $P_{\max }$ observed in this study were similar to previous observations made in well-trained triathletes (Brisswalter et al. 2000). Several hypotheses have been proposed to explain the so-called drift in $\mathrm{VO}_{2}$ at high power outputs, such as an additional oxygen cost of higher rates of $\mathrm{V}_{\mathrm{E}}$, increasing muscle and body temperatures and/or changes in muscle activity patterns and/or in fibre type recruitment (for a review, see Whipp 1994). Barstow et al. (1996) examined the physiological responses of subjects to intense exercise (half way between the estimated blond lactate threshold and $\mathrm{VO}_{2 \max }$ ) lasting $8 \mathrm{~min}$ for a range of pedalling frequencies between 45 and $90 \mathrm{rpm}$. Their results showed that the slow composent of VO2 was significantly affected by fibre type distribution but not by pedalling rates. Similarly, Billat et al. (1999) have shown that for high intensity exercise $\left(95 \% \mathrm{VO}_{2 \max }\right)$, a pedalling rate $10 \%$ lower than the freely chosen one induced the same $\mathrm{VO}_{2}$ slow component.

In the present study, in the range of pedalling rates used habitually by road cyclists (from 70 to 100 $\mathrm{rpm}$ ), no significant effects of cadence were found upon the rises in $\mathrm{VO}_{2}$ during $30 \mathrm{~min}$ of endurance exercise. Also, our data are quite different to those of Brisswalter et al. (2000) who examined cadences between 50 and $110 \mathrm{rpm}$. However, such a discrepancy could be explained by the relatively small range of cadences used in the present study. The only difference observed between cadences in this study occurred in $V_{\mathrm{E}}$ and $R$ in the first part of the exercise. High pedalling rates induced greater $\mathrm{V}_{\mathrm{E}}$ at the 5 th and 15 th min of exercise, which were associated with higher $R$ values $(>1.0)$. These data suggest a higher contribution of anaerobic metabolism to power production in the first $15 \mathrm{~min}$ at FCC + $20 \%$. Moreover, they corroborate those of Zoladz et al. (2000) who showed that beyond $100 \mathrm{rpm}$ there is a decrease in external power that can be delivered at a given $\mathrm{VO}_{2}$ with an associated earlier onset of metabolic acidosis. Importantly, this could be disadvantageous for maintained high intensity exercise. However, in the present study, such a specificity at the highest pedalling rates did not affect the continuation of the exercise since similar values of $\mathrm{V}_{\mathrm{E}}$ and $R$ were found at the end of the exercise at all three cadences.

The mean cadence spontaneously adopted by the triathletes in this study [86 (4) rpm] corroborated previous results obtained from trained cyclists or triathletes (Brisswalter et al. 2000; Lepers et al. 2000). Although it has been shown that pedalling rates could affect:

1. The maximal power during a $10 \mathrm{~s}$ sprint (Zoladz et al. 2000)

2. The power generating capabilities following high intensity cycling exercise close to $90 \%$ vo2max (Beelen and Sargeant 1993)

the reasons behind the choice of a particular cadence during endurance cycling and the corresponding GR by cyclists remain unclear.

We recently showed that cycling exercise at different pedalling rates induced changes in the neural and contractile properties of the quadriceps muscle but no significant effects of cadence were found when considering a range of FCC $\pm 20 \%$ (Lepers et al., in press). Moreover, in the present study the FCC did not appear to be more energetically optimal than FCC- $20 \%$ or FCC $+20 \%$, either at the beginning or at the end of the exercise. Brisswalter et al. (2000) have recently shown that the theoretical energetically optimal pedalling rate, corresponding to the lowest point of the parabolic V02cadence relationship, shifted progressively over the du-ration of exercise towards a higher pedalling rate (from 70 to $86 \mathrm{rpm}$ ) which was closer to the freely chosen one. Therefore, a minimisation of energy cost seems not to be a relevant parameter for the choice of cadence, at least in a non fatigued state. Actually, the choice of cadence adopted by cyclists during endurance exercise seems dependent upon factors other than the metabolic cost. Biomechanical and neuromuscular hypotheses have already been proposed to explain the choice of the pedalling rate during short-term high intensity exercise. 
However, such interesting hypotheses need to be explored during prolonged exercise.

In conclusion, the results of the present study showed that, for high intensity endurance exercise corresponding to a time trial race for example, the use of cadences in a range corresponding to the classical GR induced similar physiological effects. These data suggest that well-trained triathletes can easily adapt to the changes in cadence used habitually during racing. Further investigations are necessary to target the mechanisms involved in the choice of pedalling rate during prolonged cycling.

\section{References}

Barstow TJ, Jones AM, Nguyen PH, Casaburi R (1996) Influence of muscle fiber type and pedal frequency on oxygen uptake kinetics of heavy exercise. J Appl Physiol 81:1642-1650

Beelen A, Sargeant AJ (1993) Effect of prior exercise at different pedalling frequencies on maximal power in humans. Eur J Appl Physiol 66:102-107

Billat VL, Mille-Hamard L, Petit B, Koralsztein JP (1999) The role of cadence on the slow $\mathrm{VO}_{2}$ component in cycling and running exercise. Int J Sports Med 20:429-437

Brisswalter J, Hausswirth C, Smith D, Vercruyssen F, Vallier JM (2000) Energetically optimal cadence vs. freely-chosen cadence during cycling : effect of exercise duration. Int J Sports Med 20:60-64

Lepers R, Hausswirth C, Maffiuletti N, Brisswalter J (2000) Evidence of neuromuscular fatigue after prolonged cycling exercise. Med Sci Sports Exerc 32:1880-1886

Lepers R, Millet C, Maffiuletti N (in press) Effect of cycling cadence on contractile and neural properties of knee extensors. Med Sci Sports Exerc

Whipp BJ (1994) The slow component of $0_{2}$ uptake kinetics during heavy exercise. Med Sci Sports Exerc 26:1319-1326

Zoladz JA, Rademaker ACHJ, Sargeant At (2000) Human muscle power generating capability during cycling at different pedalling rates. Exp Physiol 85:117-124 
Table 1 Characteristics of subjects and cadences adopted [mean (SD)]. FCC Freely chosen cadence, $P_{\max }$ maximal aerobic power, $\mathrm{V}_{2 \max }$ maximal oxygen uptake

\begin{tabular}{|c|c|c|c|c|c|c|c|}
\hline $\begin{array}{c}\text { Age } \\
\text { (years) }\end{array}$ & $\begin{array}{c}\text { Mass } \\
\mathbf{( k g})\end{array}$ & $\begin{array}{c}\text { Height } \\
\mathbf{( c m )}\end{array}$ & $\begin{array}{c}\text { v02max } \\
(\mathbf{m} 1 . \mathbf{k g}-\end{array}$ & $\begin{array}{c}\text { Pmax } \\
\mathbf{( W )}\end{array}$ & $\begin{array}{c}\text { FCC } \\
(\mathrm{rpm})\end{array}$ & $\begin{array}{c}\text { FCC-20\% } \\
(\mathbf{r p m})\end{array}$ & $\begin{array}{c}\text { FCC+20\% } \\
(\mathbf{r p m})\end{array}$ \\
\hline $28(3)$ & $74(5)$ & $183(5)$ & $64.1(4.5)$ & $384(31)$ & $86(4)$ & $69(3)$ & $103(5)$ \\
\hline
\end{tabular}




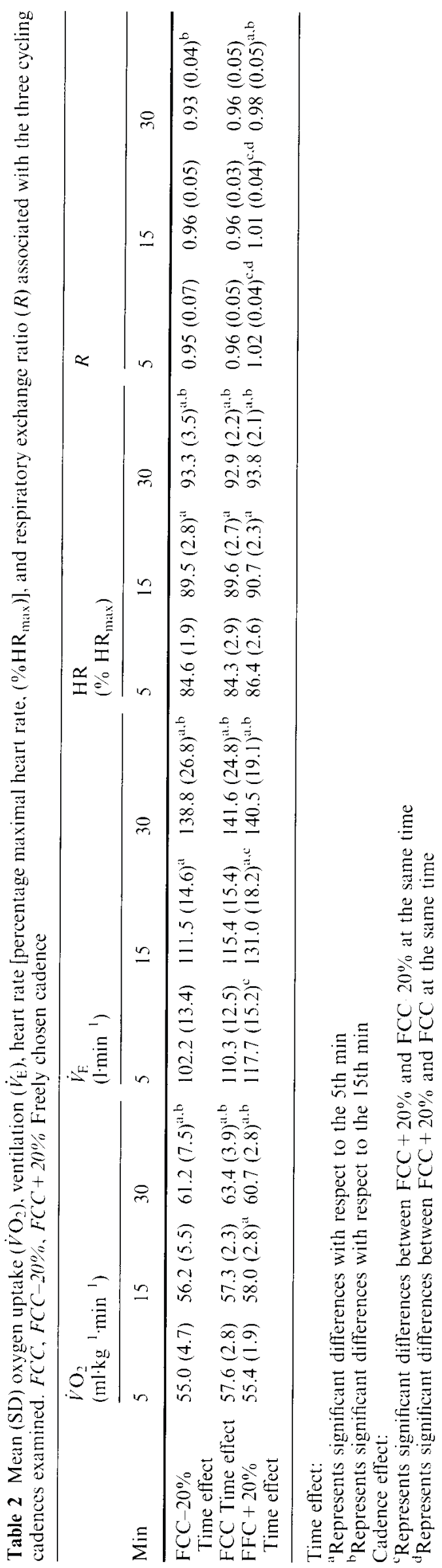

